\title{
Mathematical Modelling of Material Removal Rate and Diameter of Overcut for Sodalime glass through Pressurized Flow ECDM Process by Response Surface Methodology
}

\author{
Yugesh Kharche, Neeraj Kumar, B. B. Ahuja, M. Dhanvijay
}

\begin{abstract}
The effect of electrolyte concentration, voltage, duty factor and electrolyte flow rate on material removal rate (MRR) and diameter of overcut (DOC) of the micro-hole machining of sodalime has been studied. The experimental values changed with the theoretical calculation in the range of $3-10 \%$.

This mathematical model showed that decreasing electrolytic concentration reduces MRR and DOC. Pressurized flow Electrochemical Discharge Machining (pf-ECDM) can meet these differences. In order to put this phenomenon to use many experiments were experimented to machine holes on glass. Since parameters like electrolyte concentration, voltage, duty factor and electrolyte flow rate play an important role in MRR and DOC it needs to be calculated in order to improve the capability of this technology in machining difficult and high aspect ratio features.

A mathematical model has been extensively developed to know the role of electrolyte concentration, voltage, duty factor and electrolyte flow in MRR and $D O C$ of the process. However, machining excessive component ratio elements on ceramics like glass stays an ambitious challenge due to overcut. Although, electrical discharge machining (EDM) and electrochemical machining (ECM) are properly set up non-traditional strategies to meet these challenges, they are restrained to electrically conductive materials. In order to execute functionalities like excessive power and sustainability with minimal use of space, the raw substances used need to possess desirable mechanical, chemical and physical properties. Experimental research has been conducted, and the model was proven below various machining parameters. Demand for miniaturized merchandise is ever growing as they accomplish the venture of supplying the preferred functionalities with high efficiency using minimalistic raw material. These researches proved that growing the voltage in pf-ECDM plays a primary function in growing the MRR of the machined features.
\end{abstract}

Keywords : Mathematical modelling, MRR, DOC, Sodalime glass, $\mathrm{NaOH}+\mathrm{KOH}$.

\section{EXPERIMENTAL DETAILS}

\section{A. Experimental Setup}

The experiments have been designed primarily based on

Revised Manuscript Received on July 22, 2019.

Yugesh Kharche, $\mathrm{Ph}$. D research scholar, Mechanical engineering Department, Suresh Gyan Vihar University, Jaipur, Rajasthan, Email:yugeshkharche7@gmail.com

Dr. Neeraj Kumar, HOD, Mechanical engineering Department, Suresh Gyan Vihar University, Jaipur, Rajasthan. Email: neeraj1mech@gmail.com

Dr. B. B. Ahuja, Director, College of Engineering, Pune director@coep.ac.in.

Dr. M. Dhanvijay, Asst. Prof., Department of Production Engineering and Industrial Management, College of Engineering, Pune. Email: mrd.prod@coep.ac.in axial factor central composite designs the use of response surface design method. In this case electrolyte flow rate is the amount of mixture of air and electrolyte. The central composite design is beneficial than full factorial designs, given that it requires a great deal fewer tests and proven to be sufficient to describe the responses [1]. Where voltage is the pulsed applied voltage between the two electrodes. The sodalime glass material was machined with stainless steel (SS-304) tool electrode. Duty factor is the ratio of pulse on time to the total on and off time. Four variables such as voltage, duty factor, concentration and electrolyte flow rate were considered to ascertain their effect on material removal rate. Concentration is the mixture of $\mathrm{NaOH}$ and $\mathrm{KOH}$. Several experiments have been carried out in accordance to the design of experiment (DOE) to inspect the impact of a number of machining factors on ECDM process

\section{B. Experimental Procedure}

Work pieces were size of $75 \mathrm{~mm} \times 25 \mathrm{~mm} \times 1.3 \mathrm{~mm}$. The weights of the workpiece before and after machining were measured by a digital balance (Afcoset FX-300) with readability of $0.1 \mathrm{mg}$. Each machining was executed for 300 seconds. Measurement of hole entrance diameter was performed using vision measuring machine Make: Mitutoyo (QS-L2010ZB). The process parameters were set as DOE i.e. voltage, duty factor, concentration and electrolyte flow rate. The coded levels for all process parameters used are displayed in Table I.

Table-I: Machining parameters and their levels

\begin{tabular}{|c|c|c|c|c|c|}
\hline \multirow{2}{*}{ Parameters } & \multicolumn{5}{|c|}{ Process } \\
\cline { 2 - 6 } & $\begin{array}{c}\text { Level } \\
1\end{array}$ & $\begin{array}{c}\text { Level } \\
2\end{array}$ & $\begin{array}{c}\text { Level } \\
3\end{array}$ & $\begin{array}{c}\text { Level } \\
4\end{array}$ & $\begin{array}{c}\text { Level } \\
5\end{array}$ \\
\cline { 2 - 6 } & -2 & -1 & 0 & +1 & +2 \\
\hline Voltage (V) & 50 & 57 & 63 & 69 & 75 \\
\hline $\begin{array}{c}\text { Duty Factor } \\
\text { (D.F.) }\end{array}$ & 65 & 68 & 70 & 73 & 75 \\
\hline $\begin{array}{c}\text { Concentration } \\
\text { (C) }\end{array}$ & 40 & 45 & 50 & 55 & 60 \\
\hline $\begin{array}{c}\text { Electrolyte } \\
\text { flow rate } \\
\text { (EFR) }\end{array}$ & 1 & 2 & 3 & 4 & 5 \\
\hline
\end{tabular}

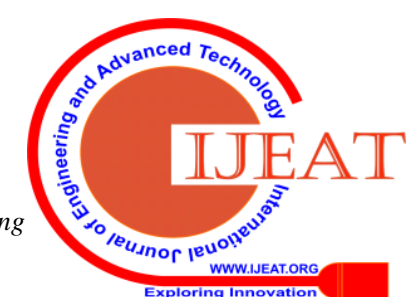


Mathematical Modelling of Material Removal Rate and Diameter of overcut for Sodalime glass through pressurized flow ECDM Process by Response Surface Methodology

The quantity of material removed was measured by using taking the difference in weights of the workpiece before and after electrical discharge machining. The MRR is expressed as the weight of material removed from workpiece over a duration of machining time in minutes. From every observation, the MRR ( $\mathrm{mg} / \mathrm{min})$ is calculated through the formulation as expressed in (1)-(2) [2]

$$
\mathrm{MRR}=\left[\left(\mathrm{W} \_1-\mathrm{W} \_2\right) / \mathrm{t}\right] * 1000
$$

Where, W1 is initial weight of work piece in grams, W2 is final weight of work piece in grams, $t$ is the machining time in minutes. Also, the diameter of overcut was measured by vision measuring machine.The experimental data used is listed in Table II.

Here, when the experimental comparison was done considering output parameters of DOC and MRR, it was found out that $\mathrm{NaOH}+\mathrm{KOH}$ had much better significance other than two other electrolytes which are $\mathrm{NaNO} 3+\mathrm{NaOH}$ and $\mathrm{NaCl}+\mathrm{NaOH}$. Hence for further investigations the values of $\mathrm{NaOH}+\mathrm{KOH}$ were considered.

\section{Response Surface Methodology}

Regression equations are observed out using software program for statistical evaluation referred to as MINITAB 17. Regression equation helps to get the relation between response variables, MRR and the input parameters such as voltage, duty factor, concentration and electrolyte flow rate.

To gain this job, linear and second-order polynomial models both were exercised to investigate the parametric effect on response criteria. The second-order model helps to understand the second-order effect of each factor separately and the two-way interaction amongst these factors combined. To perform the comparison between artificial neural network model and response surface methodology, an RSM model is established. Response surface methodology utilizes statistical design of experiment technique and least-square fitting method in the model generation phase.

An equation consisting of values of a dependent response variable and independent variables is derived for material removal rate characteristics. The same experimental data as Table II are utilized to obtain the relation between the pressurized flow ECDM process parameters and the output MRR.

Table-II: Data sets for RSM model $[\mathrm{NaOH}+\mathrm{KOH}]$

\begin{tabular}{|c|c|c|c|c|c|c|}
\hline $\begin{array}{c}\text { Sr. } \\
\text { No } \\
.\end{array}$ & VOLTAGE & CONC & EFR & D.F. & MRR & DOC \\
\hline 1 & 57 & 45 & 2 & 68 & 1.280 & 1.2555 \\
\hline 2 & 69 & 45 & 2 & 68 & 1.140 & 1.4798 \\
\hline 3 & 57 & 55 & 2 & 68 & 1.060 & 1.3785 \\
\hline 4 & 69 & 55 & 2 & 68 & 1.200 & 1.4663 \\
\hline 5 & 57 & 45 & 4 & 68 & 1.380 & 1.2117 \\
\hline 6 & 69 & 45 & 4 & 68 & 1.460 & 1.6011 \\
\hline 7 & 57 & 55 & 4 & 68 & 1.040 & 1.2223 \\
\hline 8 & 69 & 55 & 4 & 68 & 1.300 & 1.5412 \\
\hline 9 & 57 & 45 & 2 & 73 & 1.340 & 1.2080 \\
\hline 10 & 69 & 45 & 2 & 73 & 1.320 & 1.6255 \\
\hline
\end{tabular}

\begin{tabular}{|l|l|l|l|l|l|l|}
\hline 11 & 57 & 55 & 2 & 73 & 1.680 & 1.3928 \\
\hline 12 & 69 & 55 & 2 & 73 & 1.960 & 1.5363 \\
\hline 13 & 57 & 45 & 4 & 73 & 1.080 & 1.3394 \\
\hline 14 & 69 & 45 & 4 & 73 & 1.240 & 1.5549 \\
\hline 15 & 57 & 55 & 4 & 73 & 1.160 & 1.2900 \\
\hline 16 & 69 & 55 & 4 & 73 & 1.800 & 1.5578 \\
\hline 17 & 50 & 50 & 3 & 70 & 1.120 & 1.1105 \\
\hline 18 & 75 & 50 & 3 & 70 & 1.620 & 1.6066 \\
\hline 19 & 63 & 40 & 3 & 70 & 1.480 & 1.5520 \\
\hline 20 & 63 & 60 & 3 & 70 & 1.860 & 1.6121 \\
\hline 21 & 63 & 50 & 1 & 70 & 1.360 & 1.5526 \\
\hline 22 & 63 & 50 & 5 & 70 & 1.380 & 1.5127 \\
\hline 23 & 63 & 50 & 3 & 65 & 1.540 & 1.3166 \\
\hline 24 & 63 & 50 & 3 & 75 & 1.960 & 1.4833 \\
\hline 25 & 63 & 50 & 3 & 70 & 2.460 & 1.4325 \\
\hline 26 & 63 & 50 & 3 & 70 & 2.280 & 1.4760 \\
\hline 27 & 63 & 50 & 3 & 70 & 2.480 & 1.4558 \\
\hline 28 & 63 & 50 & 3 & 70 & 2.400 & 1.4089 \\
\hline 29 & 63 & 50 & 3 & 70 & 2.560 & 1.4798 \\
\hline 30 & 63 & 50 & 3 & 70 & 2.380 & 1.4060 \\
\hline
\end{tabular}

Finally, second-order model has been set up here owing to its better findings. In the general case, the response surface is described as in (2) as given in $[3,4]$ :

$$
Y_{1}=C_{0}+\sum_{i=1}^{n} C_{i} x_{i}+\sum_{i=1}^{n} C_{i i j} x_{i}^{2}+\sum_{i=1}^{n-1} \sum_{j=2}^{n} C_{i j} x_{i} x_{j}
$$

where, $\mathrm{Y} 1$ is the corresponding response that is MRR yield by using the quite a number ECDM manner variables and the xi $(1,2, \ldots, n)$ are coded ranges of $n$ quantitative technique variables, the terms $\mathrm{C} 0, \mathrm{Ci}, \mathrm{Cii}$ and $\mathrm{Cij}$ are the 2 nd order regression coefficients.

The equation of the fitted model for desired output, MRR according to the four variables $(\mathrm{x} 1=\mathrm{V}, \mathrm{x} 2=\mathrm{C}, \mathrm{x} 3=\mathrm{EFR}$ and $\mathrm{x} 4=\mathrm{DF}$ ) can be built as in (3):

\section{MRR $=-169.1+0.668 \mathrm{~V}-0.012 C+4.46 \mathrm{EFR}+4.037 \mathrm{DF}-0.007501 \mathrm{~V}^{2}-0.009008 \mathrm{C}^{2}-0.3021 \mathrm{EFR}^{2}$ $-0.03223 \mathrm{DF}^{2}+0.00326 \mathrm{~V} * \mathrm{C}+0.00534 \mathrm{~V} * \mathrm{EFR}+0.00163 \mathrm{~V} * \mathrm{DF}-0.00930 \mathrm{C} * \mathrm{EER}$ $+0,01077 \mathrm{C} * \mathrm{DF}-0,0361 \mathrm{ERR} * \mathrm{DF}$ ш m $\mathrm{m} \mathrm{m}(3)$}

Also, similar second-order model has been set up here owing to its better findings. In the general case, the response surface is described as in (4) as given in [3,4]:

$Z_{1}=D_{0}+\sum_{i=1}^{n} D_{i} y_{i}+\sum_{i=1}^{n} D_{i i} y_{i}^{2}+\sum_{i=1}^{n-1} \sum_{j=2}^{n} D_{i j} y_{i} y_{j}$

Where, $\mathrm{Z} 1$ is the corresponding response that is DOC produce by the various pf-ECDM process variables and the yi $(1,2, \ldots$, n) are coded levels of $n$ quantifiable process variables, the terms D0, Di, Dii and Dij are the 2nd order regression coefficients. 
The equation of the fitted model for desired output, DOC according to the four variables $(\mathrm{y} 1=\mathrm{V}, \mathrm{y} 2=\mathrm{C}, \mathrm{y} 3=\mathrm{EFR}$ and y4=DF) can be built as in (5):

\section{$D O C=-22.8+0.1520 \mathrm{~V}+0.0136 \mathrm{C}-0.177 \mathrm{EFR}+0.523 \mathrm{DF}-0.000668 \mathrm{~V}^{2}+0.001044 \mathrm{C}^{2}+0.0138 \mathrm{EFR}^{2}$ $-0.00332 D F^{2}-0.000645 V * C+0.00208 \nabla * E E R-0.00029 V * D F-0.00570 C * E E R$ $-0,00001 \mathrm{C} * \mathrm{DF}+0,00338 \mathrm{EFR} * \mathrm{DF} \quad \ldots \ldots(5)$}

\section{ANOVA Test}

The evaluation of variance of this model is shown in Table III and IV. The adequacy of the above two proposed models have been examined by using the analysis of variance (ANOVA). Therefore, at least one of the phrases in the regression equation makes a considerable influence on the mean response. The $\mathrm{P}$-values of the residual error $(0.059$ for MRR and 0.061 for DOC) are no longer less than $\alpha$-level (0.05). The common technique for checking the adequacy of a model is carried out through computing the F-ratio of the lack of fit to the pure error and evaluating it with the preferred value. The outcomes of the evaluation justifying the closeness of fit of the mathematical models are enumerated. Therefore, it can be concluded that the developed models given via (3) and (4) have thoroughly defined the variant in the machining parameters on MRR and DOC respectively. The values of $\mathrm{P}$ $(<\alpha$ - level) in the evaluation verify that the regression model is significant.

Table-III: Analysis of variance for material removal rate

\begin{tabular}{|c|c|c|c|c|c|}
\hline Source & DF & $\begin{array}{c}\text { Sum of } \\
\text { squares }\end{array}$ & $\begin{array}{c}\text { Mean } \\
\text { squares }\end{array}$ & F & P \\
\hline Regression & 14 & 6.38428 & 0.45602 & $\begin{array}{c}15.3 \\
7\end{array}$ & $\begin{array}{c}0.00 \\
0\end{array}$ \\
\hline Linear & 4 & 0.95259 & 0.23815 & 8.03 & $\begin{array}{c}0.00 \\
1\end{array}$ \\
\hline Square & 4 & 5.04151 & 1.26038 & $\begin{array}{c}42.4 \\
8\end{array}$ & $\begin{array}{c}0.00 \\
0\end{array}$ \\
\hline Interaction & 6 & 0.65929 & 0.10988 & 3.70 & $\begin{array}{c}0.01 \\
8\end{array}$ \\
\hline $\begin{array}{c}\text { Residual } \\
\text { error }\end{array}$ & 15 & 0.44507 & 0.02967 & & \\
\hline \begin{tabular}{c} 
Lack-of-Fit \\
\hline Pure Error
\end{tabular} & 5 & 0.39893 & 0.03989 & 4.32 & 0.06 \\
\hline Total & 29 & 6.82935 & & \multicolumn{3}{|c|}{} \\
\hline
\end{tabular}

Table-IV: Analysis of variance for diameter of overcut

\begin{tabular}{|c|c|c|c|c|c|}
\hline Source & DF & $\begin{array}{c}\text { Sum of } \\
\text { squares }\end{array}$ & $\begin{array}{c}\text { Mean } \\
\text { squares }\end{array}$ & F & P \\
\hline Regression & 14 & $\begin{array}{c}0.50334 \\
3\end{array}$ & $\begin{array}{c}0.03595 \\
3\end{array}$ & $\begin{array}{c}10.7 \\
5\end{array}$ & $\begin{array}{c}0.00 \\
0\end{array}$ \\
\hline Linear & 4 & $\begin{array}{c}0.40889 \\
3\end{array}$ & $\begin{array}{c}0 . \\
102223\end{array}$ & $\begin{array}{c}30.5 \\
6\end{array}$ & $\begin{array}{c}0.00 \\
0\end{array}$ \\
\hline Square & 4 & $\begin{array}{c}0 . \\
063868\end{array}$ & $\begin{array}{c}0 . \\
015967\end{array}$ & 4.77 & $\begin{array}{c}0.01 \\
1\end{array}$ \\
\hline Interaction & 6 & $\begin{array}{c}0 . \\
027960\end{array}$ & $\begin{array}{c}0 . \\
004660\end{array}$ & 1.39 & $\begin{array}{c}0.28 \\
0\end{array}$ \\
\hline $\begin{array}{c}\text { Residual } \\
\text { error }\end{array}$ & 15 & $\begin{array}{c}0 . \\
050169\end{array}$ & $\begin{array}{c}0 . \\
003345\end{array}$ & & \\
\hline Lack-of-Fit & 10 & 0. & 0. & 4.28 & 0.06 \\
\hline
\end{tabular}

\section{. Confirmation Test}

The settings for sodalime glass need to be in addition optimized experimentally. Optimum machining parameter combinations for specific ECDM characteristics are examined and introduced in Table $\mathrm{V}$ and VI via affirmation of experiments that confirm moderately right concurrence with prediction of response surface method. Table VI shows the evaluation between the values anticipated through the RSM using (3) and (5). The electrical discharge machining prerequisites used in the affirmation tests are in Table V. It is additionally aimed to pick suitable machining conditions for the pf- ECDM technique primarily based on the evaluation concerning several method parameters to MRR and DOC. A try is fulfilled to estimate the optimal machining setting to build the great feasible material removal rate within the experimental constraints. It has been difficult to set up models that precisely correlate the process variables and overall performance of pf-ECDM process. It is discovered that the RSM model has average deviation of 5.88 percent for DOC and 7.31 percent for MRR. The major goal of this research was to model pf-ECDM technique for optimal operation representing a trouble in the manufacturing environment where, it is no longer feasible to outline the optimization objective feature the use of a smooth and continuous mathematical formula. Accordingly, RSM is validated to be a practical and effective way for the comparison of pf-ECDM material removal rate. It is aimed to enhance a methodology the usage of an input-output sample of statistics from an pf-ECDM technique to solve each the modelling and optimization problems.

\begin{tabular}{|c|c|c|c|}
\hline VOLTAGE (V) & CONC (\%) & EFR (ml/min) & D.F. \\
\hline 54 & 58 & 2 & 74 \\
\hline 64 & 51 & 4 & 69 \\
\hline 74 & 44 & 5 & 66 \\
\hline
\end{tabular}

Table-V: ECDM conditions in verification test 
Mathematical Modelling of Material Removal Rate and Diameter of overcut for Sodalime glass through pressurized flow ECDM Process by Response Surface Methodology

Table-VI: ERROR FOR PREDICTED VALUES OF MRR AND DOC MODEL WITH RSM

\begin{tabular}{|c|c|c|c|c|c|c|}
\hline \multirow{2}{*}{ Sr. No. } & \multicolumn{2}{|c|}{ MRR (g/min) } & \multirow{2}{*}{$\begin{array}{l}\text { Error } \\
(\%)\end{array}$} & \multicolumn{2}{|c|}{ DOC (mm) } & \multirow{2}{*}{$\begin{array}{c}\text { Error } \\
(\%)\end{array}$} \\
\hline & $\begin{array}{l}\text { Experimental } \\
\text { value }\end{array}$ & RSM predicted & & $\begin{array}{l}\text { Experimental } \\
\text { value }\end{array}$ & RSM predicted & \\
\hline 1 & 1.7000 & 1.7636 & 6.36 & 1.2624 & 1.2039 & 5.85 \\
\hline 2 & 2.3400 & 2.4367 & 9.67 & 1.3166 & 1.3997 & 8.31 \\
\hline 3 & 0.7400 & 0.6769 & 5.89 & 1.4408 & 1.4060 & 3.48 \\
\hline
\end{tabular}

\section{CONCLUSION}

From the experiments that had been performed on sodalime glass material with pf -ECDM and the RSM models developed, the following interesting conclusions have been drawn.

i. The material removal rate increases as the voltage and concentration increases on the other hand increase of duty factor and electrolyte flow rate causes lower MRR and DOC.

ii. Among the four variables applied voltage possesses the highest influence on material removal rate whilst duty factor appears the least influence on MRR and DOC.

iii. The developed models are inside the limits of agreeable error when experimental and model values are compared for all overall performance measures considered.

\section{REFERENCES}

1. U. Caydas, and A. Hascalik, "Modeling and analysis of electrode wear and white layer thickness in die-sinking EDM process through response surface methodology," Int. J. Adv. Manufac. Technol., vol. 38, pp.1148-1156, 2008.

2. M. R. Dhanvijay, B. B. Ahuja, "Performance enhancement of ECDM process on $\mathrm{A} 12 \mathrm{O} 3$ ceramics using tubular tool", International Journal of Scientific \& Engineering Research, Volume 6, Issue 7, July-2015, pp. 369-373

3. Rahman, Prof. Dr. Md. Mustafizur \& Khan, Dr. Md. Ashikur \& Kadirgama, Kumaran \& Noor, M.M. \& Abu Bakar, Rosli. (2010). Mathematical modeling of material removal rate for Ti-5Al-2.5 Sn through EDM process: a surface response method. 34-37.

4. M. M. Rahman, et. al., (2010). Modeling of Material Removal on Machining of Ti-6Al-4V through EDM using Copper Tungsten Electrode and Positive Polarity. 1319 - 1324 